\title{
Spatial Citizenship: The Concept of Competence
}

\author{
Inga GRYL ${ }^{1}$, Uwe SCHULZE ${ }^{2}$ and Detlef KANWISCHER ${ }^{2}$ \\ ${ }^{1}$ University of Koblenz-Landau/Germany·gryl@uni-landau.de \\ ${ }^{2}$ Goethe-University Frankfurt/Germany
}

This contribution was double-blind reviewed as full paper.

\begin{abstract}
When translating the Spatial Citizenship (SPACIT) approach into practical learning environments, an appropriate competence model becomes essential. Based on previous deliberations for preparing SPACIT for curriculum implementation this paper illustrates the systematic production of a competence framework for SPACIT education for teacher training courses. Founded on a content analysis of the scholarly literature on the SPACIT approach, the construction is conducted as a three step method including the consideration of influential international competence models (e.g. the body of knowledge concerning GIScience \& Technology, DIGCOMP, CEFR, ITEC) and material from neighbouring domains (e.g. philosophy, communication theory, geography, pedagogy).
\end{abstract}

\section{Introduction}

Within the EU-funded SPACIT project, competence modelling is regarded as essential for the sound development of a curriculum, learning environments and teaching materials for teacher training courses. These resources will enable teachers to educate their pupils with a SPACIT approach and will accordingly pave the way to implement education for SPACIT in schools as an answer to everyday societal challenges and opportunities introduced by current geo-media. A SPACIT competence model will express educational standards as coherent statements of knowledge, skills, abilities, and attitudes. The objectives of this model are not to support competence assessment and measurement, but to serve as orienttation for teachers to actively organize their learning processes, and to reflect on their learning needs and strategies.

This paper is based on previous deliberations for the formulations of SPACIT competences (KANWISCHER, SCHULZE \& GRYL 2012) that serve as a preparation for a SPACIT competence model which in turn is based on the theoretical approach of SPACIT as formulated by GRYL \& JEKEL (2012). As a second main reference paper for the formulation of the SPACIT competence model, QUADE \& FELGENHAUER (2012) will be considered here. These papers provide the main foundations of SPACIT that shall be considered in the SPACIT competence model: an emancipatory citizenship education (cf. BENNETT, WELLS \& RANK 2009; MITCHELL \& ELWOOD 2012), the mature appropriation of space (cf. PAASI 1986; WERLEN 1993; LEFEBVRE 1993; MASSEY 1998) and the competent utilization of geomedia in reflexive consumption and production processes (cf. HARLEY 1989; MACEACHREN 1992; SCHUURMAN 2000; PICKLES 2006; CRAMPTON 2009). Additionally, a working 
definition of SPACIT competence has to be derived from these two sources, since competence development is based on the exact definition of learning objectives (cf. HARTIG 2006).

Within the SPACIT competence model, the term 'competence' is used based on KOEPPEN, Hartig, Klieme \& Leutner (2008) and Klieme, Vollmer, Tenorth, Gruber, Döbrich, Blum, AVEnarius, ReISS \& Rost (2007) as learnable and context-specific (cognitive) dispositions aiming at the empowerment of the individual in unfamiliar everyday problem situations. In accordance with the definition of key competences for lifelong learning (EUROPEAN PARLIAMENT AND COUNCIL 2007: 13), competences are defined as combinations of knowledge, skills and attitudes, whereby knowledge is the outcome of the assimilation of information through learning, skills are understood as the ability to apply knowledge and use strategic knowledge to complete tasks and to solve problems, and attitudes are regarded as the integration of individual characteristics, personality traits, motivations and values of perceiving, living and interacting with others in a social context (EUROPEAN COMMISSION 2008: 11). SPACIT competence is therefore defined as the ability to participate in fluent communities and society and to challenge dominant discourses by producing, communicating and negotiating alternative spatial constructions with the help of geo-media, used in a reflected and reflexive manner ${ }^{1}$. On this basis, the paper aims to answer the following two research questions: Which competences have to be taken into account for SPACIT education in general? How could they be brought together in an appropriate structure in terms of a competence model that serves as a foundation for the development of a curriculum for teacher education to support active learning of SPACIT in the classroom?

Section 2 describes the method of the modelling of the SPACIT competence model, whereas the following sections illustrate the execution of the steps suggested in section 2, including content analysis of the fundamental theoretical papers as well as contributions from existing competence models from neighbouring fields on EU and international level, and additional material from other neighbouring domains. Section 5 outlines the SPACIT competence model, while section 6 provides an outlook on further research and opportunities within and beyond the SPACIT project founded on the SPACIT competence model.

\section{Methodological Approach}

The SPACIT approach (GRYL \& JEKEL 2012) serves as the backbone of the SPACIT competence model. Therefore, certain reference points regarding the domains involved and the normative cornerstones have to be considered. This is achieved by a content analysis of papers central to the concept as well as additional material preparing the idea for its translation into a systematic, well-structured and teachable set of competences. The following steps are performed to formulate competences and develop the SPACIT competence model:

\section{Step1: Identification of SPACIT competence dimensions}

According to the existing practice of competence modelling, 'competence dimensions' constitute the framework of a competence model, while corresponding sub-categories allow

1 Meaning to be critical towards both the medium and one's own interaction with the medium (see also section 5 below). 
for the attribution of competences to that structure. Dimensions and an initial number of sub-categories are extracted from two key papers on the theoretical conceptualisation of the SPACIT approach, GRYL \& JEKEL (2012) and QUADE \& FELgENHAUER (2012). The method applied for extraction is systematic text analysis/systematic content analysis according to MAYRING (2008), which allows for an inductive category construction. Section 3 will display the dimensions in more detail.

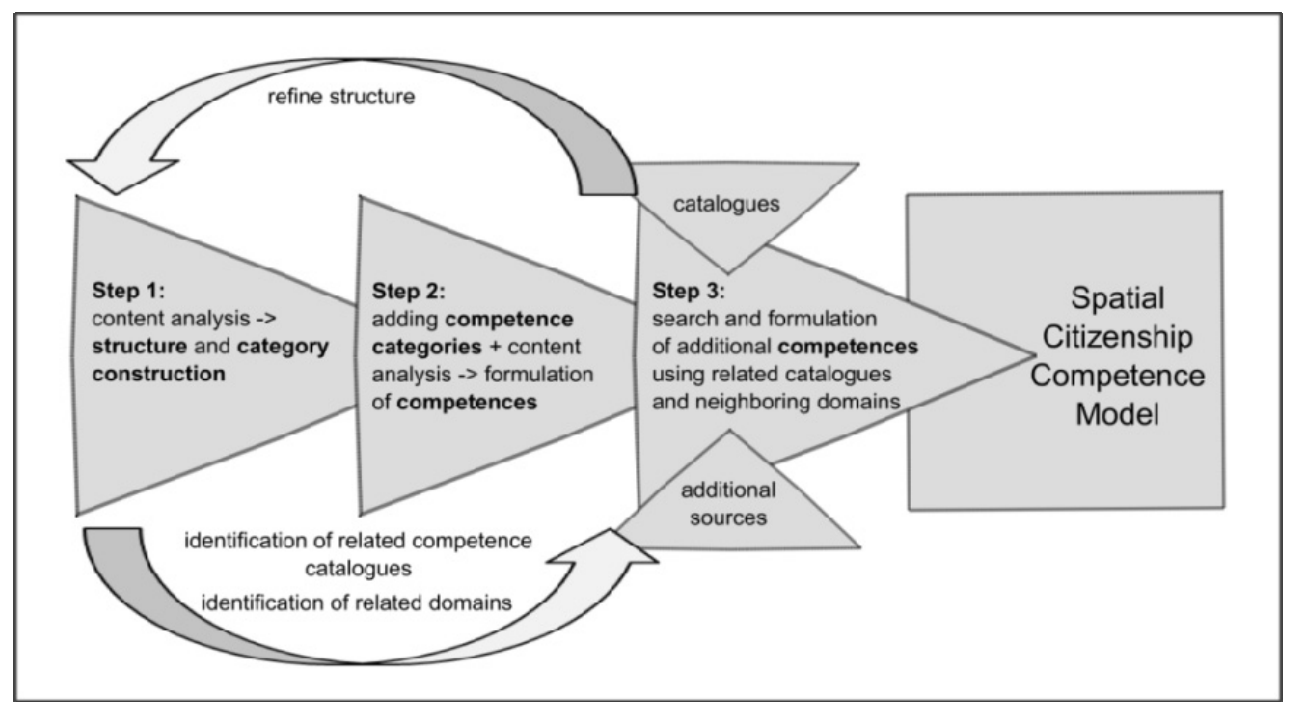

Fig. 1: Methods used to develop the structure of the SPACIT competence model (own diagram)

\section{Step 2: Construction of the SPACIT competence matrix}

In this step, an additional transversal structure is added to the framework of dimensions and subcategories, involving the elements of knowledge, skills and attitudes (abbreviated as KSA). This leads to a matrix of competence dimensions and competence elements which is systematically filled with text data/samples following the content analysis of the basic papers, while re-formulating them as learning outcomes (i.e. different facets of SPACIT competences). This includes a revision and reorganization of the previously formulated competence dimensions and sub-categories in feedback loops to avoid redundancies and ensure consistency.

\section{Step 3: Adding categories and competences from additional sources}

Resulting from the requirements of a competence model dedicated to systematically structuring learning environments, the content analysis of the basic theoretical construct leaves some blank areas. Therefore, additional material from two main sources is included:

- Competence catalogues: Catalogues are selected firstly, due to their intersections with aspects of the SPACIT concept, and secondly, based on their status within EU and 
international educational discourses. The extraction of competences from these catalogues is orientated firstly at the categories formulated in the previous steps and secondly inspired by the material itself following a mixture of theoretical heuristics and grounded theory (BLUMER 1954; GLASER \& STRAUSS 1998). Competences are finally harmonized towards a congruent language and congruent learning objectives corresponding to the normative backbone of SPACIT.

- References from neighbouring domains: These references in the semantic field around SPACIT theoretically strengthen the approach and make it conveyable in the shape of competences.

\section{Structure and Keywords of the SPACIT Approach}

Based on the aforementioned content analysis and category development, the SPACIT competence model is structured by six dimensions (see Fig. 2). The dimensions are related to the application of KSA in the field of generic competences, involving instrumental competence (e.g. communication skills, information management skills) and interpersonal competences (e.g. social interaction, collaboration and teamwork skills).

The core dimensions of 'Geo-media technology and methodology domain' (or 'Technology and methodology to handle geo-media'), 'Reflection on the use of geo-media', and 'Communication with geo-media' correspond to the structure of the SPACIT concept (GRYL \& JEKEL 2012), with the modification that 'spatial representations', as originally stated (ibid.), are replaced by the term 'geo-media' as the main focal point of the SPACIT project. A more detailed list of the competence dimensions is as follows:

- The area of 'Geo-media technology and methodology Domain' refers to technological maturity, creativity and geoinformation (GI) skills to enable the use of (mainly Web 2.0-based) geo-media concerning consumption, production and communication processes.

- 'Reflection on the use of geo-media' displays the ability to reflect geo-media as social construction and the usage of geo-media, which leads to thinking in alternative spatial constructions. It also links to the awareness of the influence of geo-media on everyday social action.

- 'Communication with geo-media' marks the ability to express, communicate, and negotiate alternative spatial constructions with geo-media. It is based on the concept of argumentation and negotiation as nonlinear processes that serve specific interests and can challenge societal discourses.

- The dimensions of 'Spatial Domain' and 'Citizenship Education Domain', related to subject-specific KSA, are horizontal layers underpinning the core dimensions overall. The 'Spatial Domain' as main cornerstone of SPACIT links to relative concepts of space (social construction of spaces) as well as absolute concepts of space (physical space and spatial thinking)

- The 'Citizenship Education Domain' refers to emancipatory concepts of citizenship education, based on awareness of power relations in society and the conviction of the importance of democratic negotiation processes/participation in fluent communities.

- 'Implementation strategies' are not incorporated within the other dimensions, but link them to the significant aspect of SPACIT education. Following QUADE \& FELGEN- 
HAUER (2012), 'Implementation strategies' are justified by the need for the creation of reflective and reflexive learning situations as well as ongoing professional development of educationists involved.

\section{Contributions from Additional Competence Catalogues and Neighbouring Domains}

In order to arrive at an elaborated substructure of the dimensions of the SPACIT competence model additional input from related domains and competence catalogues have been processed based on the determination of the main categories of SPACIT competence. Summarising a comprehensive body of literature, the following contributions are most relevant.

\subsection{Digital media competence}

Owing to the importance of digital media competence within the framework of SPACIT education for SPACIT competences modelling the outcomes of the project 'Digital Competence yields the following results: Identification and Europe-wide validation of its key components for all levels of learners (DIGCOMP) are important (cf. ALA-MUTKA 2011; FERRARI 2012). Within DIGCOMP digital competence is mapped as a multi-layered competence construct that is considered "a higher level concept than simply being able to use digital tools and media" (ALA-MUTKA 2011: 53). The model of digital competence includes an overlapping field of multiple literacies like Internet literacy, Information and Communication Technologies (ICT) literacy, media literacy and information literacy and is structured by three major elements: (i) 'instrumental knowledge and skills' for tool and media usage (i.e. operational and medium related); (ii) 'advanced skills and knowledge' for communication and collaboration, information management, learning and problem-solving and meaningful participation; and (iii) 'attitudes' described as intercultural, critical, creative, responsible and autonomous.

\subsection{Communication competence}

Communication competence for SPACIT education can be summarised in three strands: (i) communication as discursive processes (i.e. sharing ideas and meanings using online and offline communication paths); (ii) communication with spatial representations; and (iii) communication with digital geo-media (i.e. expressing spatial constructions with the help of geo-media). In order to emphasise multi-layered communication processes within SPACIT, competence modelling must not just include technical aspects related to digital media competence alone, but has to be fundamentally connected to the general concepts of communication competence (cf. BAGARIĆ \& MiHALJEVIĆ DJIGUNOVIĆ 2007). Therefore, SPACIT communication competence is related to the Common European Framework of Reference for Languages (CEFR) by the COUNCIL OF EUROPE (2001) that has become a key reference document across Europe, comprehensively describing the knowledge and skills necessary for communication as well as the situations and domains of communication. The CEFR follows an 'action-oriented' approach which means that the users/learners of a language are understood "as 'social agents', i.e. members of society who have tasks (not exclusively language-related) to accomplish in a given set of circumstances, in a specific 
environment and within a particular field of action." (COUNCIL OF EUROPE 2001: 9). According to this, communication competence in SPACIT is based on the two major interrelated meta-categories of (i) 'communicative language activity' which is understood as a set of parameters and categories describing what a person is able to do with a language and what s/he should know in order to be able to act (ibid.: 43); and (ii) 'communicative language competences' that comprise several elements of linguistic, sociolinguistic and pragmatic competence, each of which being made up of knowledge, skills and know-how (ibid.: 13).

\subsection{Teachers' digital literacy}

The SPACIT competence model will form the basis for education for SPACIT in terms of both teacher education and the creation of innovative and geomedia-centred learning environments that allow for a critical engagement with geoinformation and geospatial representations (cf. QUADE \& FELGENHAUER 2012). Therefore, the formulation of the SPACIT competence model also incorporates the findings of the project 'Innovative Technologies for Engaging Classrooms' (iTEC). In particular, the outcomes of work package D4.1 'Teacher skills and competence development for classrooms of the future' (cf. PEDRO, MAtos, PEDRO \& ABRANTES 2011). In iTEC a set of five major domains of teachers' digital literacy was established (i.e. technical-pedagogical competences) (ibid.). While the two components of 'Digital Knowledge' and 'Social \& Ethical' are already part of other SPACIT (sub-)categories, the fields of 'Planning \& Management', 'Classroom practices', and 'Professional Growth' (ibid.) are adapted for creating further substructures within the SPACIT competence model.

\subsection{Contribution from Citizenship Education (CSE)}

As introduced by GRYL \& JEKEL (2012) and further discussed by QUADE \& FELGENHAUER (2012), the represented theoretical concepts of Citizenship Education (CSE) by BENNETT et al. (2009) already form an elaborated foundation for the further structuring of the categories and competence components related to the dimension of 'citizenship education' within the SPACIT competence model. Beside this, additional contributions should also take into account the actual outcomes of CSE from the European perspective to make the SPACIT approach generally linkable to the development of civic competences in terms of participation in the social and political life. CSE in European countries covers a comprehensive range of objectives, knowledge and skill areas (cf. EDUCATION, AUDIOVISUAL AND CULTURE EXECUTIVE AGENCY (EACEA) 2012). For the purpose of SPACIT education, especially the following four skill areas of CSE are most relevant which are defined as being essential for pupils and students to acquire for to become active and responsible citizens (ibid.): (i) civic-related skills, (ii) social skills, (iii) communication skills and (iv) intercultural skills.

\subsection{Contribution from the Geographic Information Science and Technology Domain}

Representing a most comprehensive knowledge domain this field integrates even extensive sub-domains of (i) Geographic Information Science (GIScience), (ii) Geospatial Technology and (iii) Applications of Geographic Information Science and Technology (GIS\&T) 
in public, professional and private realms (cf. DiBIASE, DEMERS, JOHNSON, KEMP, LUCK, PLEWE \& WENTZ 2006). According to GRYL \& JEKEL (2012), within SPACIT the GIS\&T domain is even less developed which is mainly due to the requirement of low technical requirements to access and utilize geomedia via Web 2.0 technologies. Following QUADE \& FELGENHAUER (2012), this argument is also supported by the central aspect of the integration of geographic ICT in everyday practises of lay people who have no formal qualification or professional experience with the use of digital geospatial technologies. Therefore, SPACIT competence modelling draws on structured approaches of GIS\&T competence to arrive at an appropriate substructure. As already introduced in GRYL \& JEKEL (2012), the concept of the Digital Earth Brainware Framework by STROBL (2008) (in detail the categories $\mathrm{C} 1$ to $\mathrm{C} 3, \mathrm{~A} 1, \mathrm{~T} / \mathrm{A}$ ) is hence implemented in the SPACIT competence model as a framework for the formulation of the dimension of 'Geomedia technology and methodology domain'. To come to a detailed nomination of necessary KSA within this dimension the Benchmark Statements for GIS in Geography Education by the HERODOT NETWORK (cf. DONERT 2009) as well as the proposed Benchmark Statements for Teacher Training and Education in Europe by the Digital-Earth.EU network (LINDNER-FALLY \& ZWARTJES 2012) are further integrated.

\subsection{Contribution from the domain of Geography}

As discussed in KANWISCHER et al. (2012), within SPACIT relations to the field of gegraphy are explicitly made through the construction of the competence dimension 'Spatial Domain' and its partition into the strands of (i) 'relative concepts of space' (LEFEBVRE 1993; WERLEN 1993; PAASI 1986) and (ii) 'absolute concepts of space' (NATIONAL RESEARCH COUNCIL (NRC) 2006).

\section{The SPACIT Competence Model}

Based on the structure of the SPACIT competence dimensions (section 3) Figure 2 shows the SPACIT competence model in detail. In this tabular scheme the columns represent the SPACIT competence dimensions, their single components as well as the particular KSA further clustered into groups. The rows mark the affiliation of the single SPACIT competence dimensions within the competence model based on their distinctive function and, hence, can be summarized as 'SPACIT Core Competences' (i.e. instrumental and interpersonal competences); 'Subject-specific Competences'; and 'Framing Category for SPACIT Implementation' (i.e. systemic competence). Each competence dimension is sub-divided into at least two competence components. The first one is labelled as 'Meta-level'. It gives the rationale for each dimension in the context of the SPACIT concept, describing the overarching KSA fundamental to all other sub-categories of the particular dimension. Besides this, coherent competence element there are further individual components described as follows:

\section{SPACIT Core Competences}

- Geomedia information processing: This area contains the KSA necessary for the mature handling of geodata within Web 2.0-based geomedia based on technical as well as methodological GIS\&T skills concerning activities as well as processes of con- 
sumption, production and prosumption of geomedia, analysis carried out using geomedia as well as aspects of technical communication in the form of social networking.

- Reflective consumption of geomedia: Referring to the dimension of 'Reflection on the use of geomedia', this component describes the KSA fundamental to think about the role and the impact of geomedia as social constructions.

- Reflexive consumption of geomedia: Referring to the dimension of 'Reflection on the use of geomedia' this areas contain the KSA the user needs to be reflexive towards her/his own geomedia consumption by being conscious of her/his own hypothesis construction. This involves awareness of the influence of geomedia on one's own and people's everyday actions.

- Communicative activities and strategies: Within the field of 'Communication with geomedia' strategic communication competence contains the KSA needed to carry out tasks and to perform certain activities/ actions in order to achieve or avoid an intended objective within a (spatial) problem solving as well as a discourse process. This is understood as organising, purposefully expressing and sharing one's own and others' spatial visions and constructions through communication processes using spatial and non-spatial visualisations as well as various media like text, pictures, and drawings etc. embedded into discursive geomedia environment, involving communicative activities of reception, production, interaction and mediation.

- Socio-linguistic competence: Within the field of 'Communication with geomedia' socio-linguistic communication competence describes the KSA needed to appropriately communicate between representatives of different (cultural) communities or institutional groups sticking to the social conventions, norm and rules. Above all, this is connected to intercultural competence to be able to reflexively compare one's own position/ membership in a particular (fluent) community with the one of members of a certain target community, and, hence, to avoid misunderstandings and conflicts.

- Pragmatic competence: Within the field of 'Communication with geomedia' pragmatic communication competence contains the KSA necessary for the individual to effectively perform (spatial) communicative functions in an (non-)linear interactive and discursive way, discerning the principles according to which messages are organised, structured and arranged.

\section{Subject-specific Competences}

- Relative concepts of space: Referring to the 'Spatial Domain', this competence contains the KSA that work as a basis to understand and apply the efficacy of geomedia as instruments to structure action in space by the construction of spaces. It refers to the appropriation of spaces that connects the constructions of spaces by the attachment of meanings to matter with societal power relations and social action and in spaces. 


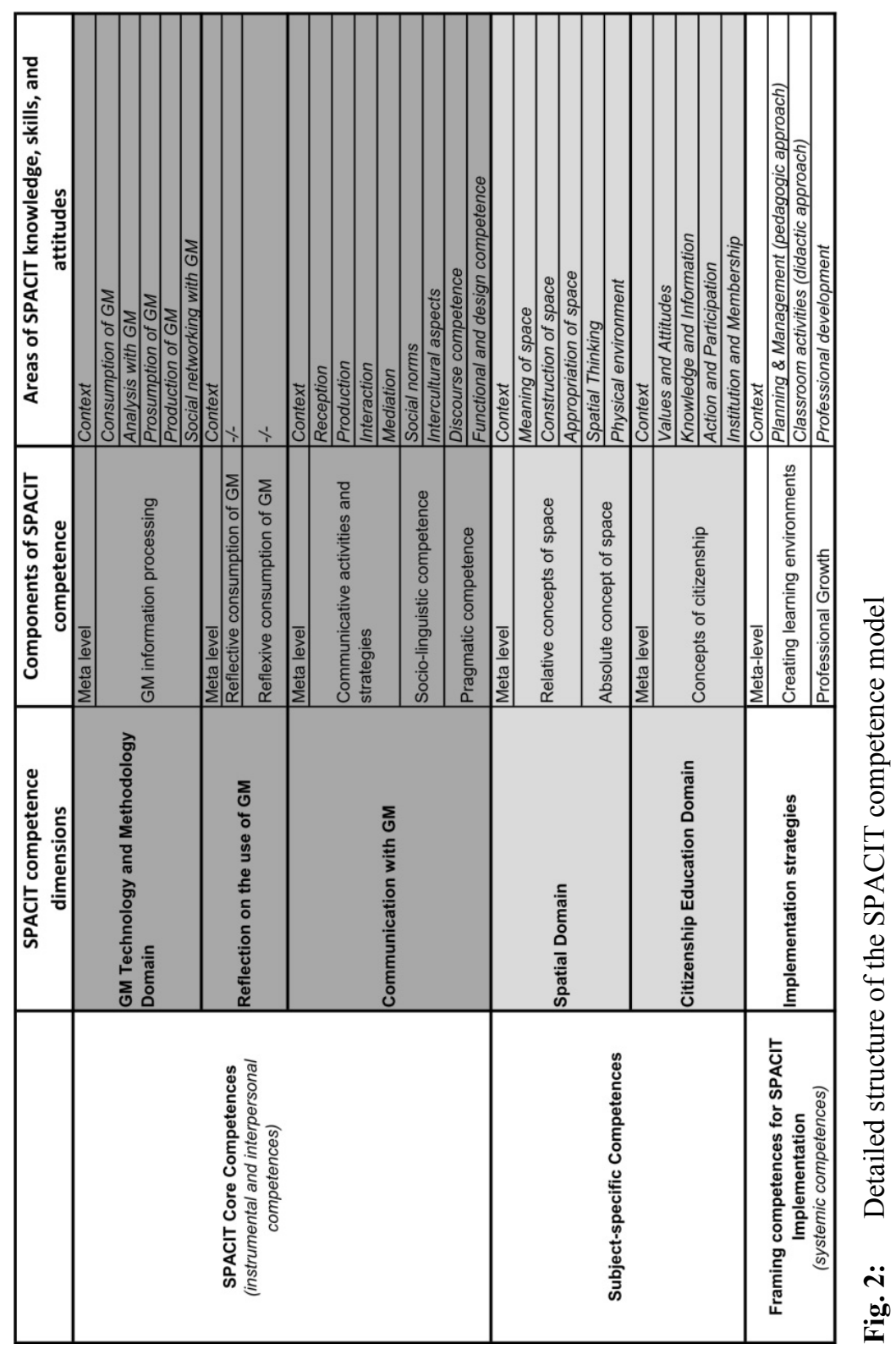


- Absolute concepts of space: As second component in the 'Spatial Domain', this competence contains the KSA rested on absolute concepts of space which are crucial for working with geomedia and understanding spatial relations. It links to the approach of Spatial Thinking and the concept of physical matter with its non-deterministic influence on spatial structures.

- Concepts of citizenship: Based on emancipatory concepts of citizenship, this competence links to key values for SPACIT, namely democratic principles and fundamental human rights, as well as to the KSA necessary for participation in society against the background of considering societal rules as fundamentally negotiable. 'Concepts of citizenship' also includes KSA to act as Spatial Citizen based on an understanding of the role of institutions and fluent (new media) communities.

\section{Framing competences for SPACIT Implementation}

- Creating learning environments: This competence links to the KSA essential to plan and manage learning environments (i.e. pedagogical approach) and to design and act in classroom situations (i.e. didactical approach). While the first approach refers to the meta-level of teaching SPACIT, including reflection and evaluation, the second relates to specific and situational actions for teaching professionals.

- Professional Growth: This competence refers to the need for each teacher to develop competences in the areas linked to SPACIT. Related KSA include the abilities and willingness to use (online) learning tools, to visit and use the related learning environments, and to reflect on own competences and competence development.

\section{Outlook}

The SPACIT competence model functions as a basis for the development of teacher training courses for SPACIT education. The upcoming tasks are first of all, the formulation of a connecting curriculum, including the formulation of learning outcomes and measures which can be used to reach the competences suggested. These will state what the learner is expected to be able to do, whereby formulations will be orientated at the phrase "the teacher can enable pupils to...". This curriculum shall also provide statements of workloads according to the European Credit Transfer System (ECTS) in order to support the harmonisation and implementation in various national initial and further teacher training activities. Second, the production of a SPACIT curriculum plan and framework provided for national and local initial teacher training and in-service teacher education. Based on the ECTS, the SPACIT curriculum will comprise a detailed description of the particular learning modules containing learning outcomes, qualifications and workloads as well as aspects of quality assurance. Based on these processes, teaching and learning materials will be developed and subsequently evaluated and refined in collaboration with teachers at school.

\section{Acknowledgements}

Research for this contribution has been funded by the SPACIT Comenius multilateral project of the European Commission. 


\section{References}

Ala-MutKA, K. (2011), Mapping Digital Competence: Towards a Conceptual Understanding. Technical Note. European Commission. Joint Research Centre. Institute for Prospective Technological Studies. Luxembourg: Publications Office of the European Union. http://ipts.jrc.ec.europa.eu/publications/pub.cfm?id=4699 (July 2012).

BAGARIĆ, V. \& DJIGUNOVIĆ, J. M. (2007), Defining communicative competence. Metodika, 8, (1), 94-103. http://hrcak.srce.hr/file/42651 (December 2012).

Bennett, W. L., Wells, C. \& RanK, A. (2009), Young citizens and civic learning. Citizenship Studies, 13 (2), 105-120.

Blumer, H. (1954), What is wrong with social theory? American Sociological Review, 19 (1), 3-10.

COUNCIL OF EUROPE (2001), Common European Framework of Reference for Languages: Learning, Teaching, Assessment. Cambridge, Council of Europe.

Crampton, J. W. (2009), Cartography: Maps 2.0. Progress in Human Geography, 33 (2), 99-100.

DiBiase, D., DeMers, M., Johnson, A., Kemp, K., Luck, A., Plewe, B. \& Wentz, E. (2006), Geographic information science and technology body of knowledge. Washington, DC.

DONERT, K. (2009), Benchmarking GIS - a Charter for European Education. In: JEKEL, T., Koller, A. \& DONERT, K. (Eds.), Learning with Geoinformation IV. Heidelberg, Wichmann, 2-11.

Education, Audiovisual And Culture Executive Agency (EACEA) (2012), Citizenship Education in Europe. Brussels: EACEA.

http://eacea.ec.europa.eu/education/eurydice/documents/thematic_reports/139EN.pdf (November 2012).

EUROPEAN COMMISSION (2008), The European Qualifications Framework for Lifelong Learning (EQF). Luxembourg: Office for Official Publications of the European Communities. http://ec.europa.eu/education/pub/pdf/general/eqf/broch_en.pdf (November 2011).

EUROPEAN PARLIAMENT AND COUNCIL (2007), Key Competences for Lifelong Learning. European Reference Framework. Luxembourg: Office for Official Publications of the European Communities. http://ec.europa.eu/dgs/education_culture/publ/pdf/lllearning/keycomp_en.pdf(April 2013).

FERRARI, A. (2012), Digital Competence in Practice: An Analysis of Frameworks. Technical Report. European Commission. Joint Research Centre (JRC). Institute for Prospective Technological Studies. Luxembourg: Publications Office of the European Union. http://ftp.jrc.es/EURdoc/JRC68116.pdf (December 2012).

Glaser, B. G. \& StRauss, A. L. (1998), Grounded Theory. Bern, Huber.

GRYL, I. \& JEKEL, T. (2012), Re-centering GI in secondary education: Towards a spatial citizenship approach. Cartographica, 47 (1), 18-28.

HARLEY, J. B. (1989), Deconstructing the map. Cartographica, 2, 1-20.

Hartig, J. \& Klieme, E. (2006), Kompetenz und Kompetenzdiagnostik. In: ScHWEIzER, K. (Ed.), Leistung und Leistungsdiagnostik, Berlin, Springer, 127-143.

Herodot NeTwORK (2009), The Benchmarking Statements for GIS in Geography Education. In: JeKel, T., Koller, A. \& DONERT, K. (Eds.), Learning with Geoinformation IV. Heidelberg, Wichmann, 235-240. 
Jo, I. \& BeDnARZ, S. (2009), Evaluating Geography Textbook Questions from a Spatial Perspective: Using Concepts of Space, Tools of Representation, and Cognitive Processes to Evaluate Spatiality. Journal of Geography, 108, 4-13.

KAnwischer, D., Schulze, U. \& GRYL, I. (2012), Spatial citizenship. A case for a curriculum. In: CAR, D., Strobl, J., Jekel, T. \& Griesebner, G. (Eds.), GI_Forum 2012: Geovisualistion, Society and Learning. Berlin/Offenbach, Wichmann, 172-181.

Klieme, E., Vollmer, H. J., Tenorth, H.-E., Gruber, H., Döbrich, P., Blum, W., Avenarius, H., ReIss, K. \& Rost, J. (2007), The Development of National Educational Standards: An Expertise. Berlin, The Federal Ministry of Education and Research (BMBF).

Koeppen, K., Hartig, J., Klieme, E. \& Leutner, D. (2008), Current Issues in Competence. Modeling and Assessment. Journal of Psychology, 216 (2), 61-73.

LefeBVRE, H. (1993), The Production of Space. Oxford, Blackwell.

LindNER-FALLY, M. \& ZWARTJES, L. (2012), Learning and Teaching with Digital Earth Teacher Training and Education in Europe. In: CAR, D., STROBL, J., JEKEL, T. \& GRIESEBNER, G. (Eds.) (2012), GI_Forum 2012: Geovisualistion, Society and Learning. Berlin/Offenbach, Wichmann, 272-282.

MACEACHREN, A. M. (2004), How maps work. New York, Guilford Press.

MASSEY, D. (1998), Power geometries and the politics of space-time. Heidelberg, Department of Geography.

MAYRING, P. (2008), Qualitative Inhaltsanalyse. Grundlagen und Techniken. Weinheim, Beltz.

Mitchell, K. \& Elwood, S. (2012), Children's Politics and Civic Engagement: Past, Present, and Future. Presentation at the AAG Annual Meeting, 2012-02-26, New York.

NATIONAL RESEARCH COUNCIL (NRC) (2006), Learning to think spatially. GIS as a support system in the K-12 curriculum. Washington, DC, National Academies Press.

PAASI, A. (1986), The institutionalization of regions. Fennia, 1, 105-146.

Pedro, N., MAtos, J. F., Pedro, A. \& Abrantes, P. (2011), Teacher skills and competence development for classrooms of the future. iTEC Deliverable 4.1. Teachers' Competence. http://itec.eun.org/web/guest/results (March 2012).

PICKLES, J. (2006), Ground Truth 1995-2005. Transactions in GIS, 10 (5), 763-772.

Quade, D. \& Felgenhauer, T. (2012), Some aspects of social theory for the SPACIT competence model. SPACIT project, WP1, unpublished working paper.

SchuURMAN, N. (2000), Trouble in the heartland: GIS and its critics in the 1990s. Progress in Human Geography, 24, 569-690.

The European Parliament \& THE European Council (2006), Recommendation of the European Parliament and Council on Key Competences for Lifelong Learning. http://eurlex.europa.eu/LexUriServ/LexUriServ.do?uri=OJ:L:2006:394:0010:0018:en:PDF (March 2012).

WERLEN, B. (1993), Society, action, and space. London, Routledge. 